\title{
Cochrane
}

Library

Cochrane Database of Systematic Reviews

\section{Slow-release fluoride devices for the control of dental decay} (Review)

Chong LY, Clarkson JE, Dobbyn-Ross L, Bhakta S

Chong LY, Clarkson JE, Dobbyn-Ross L, Bhakta S.

Slow-release fluoride devices for the control of dental decay.

Cochrane Database of Systematic Reviews 2018, Issue 3. Art. No.: CD005101.

DOI: 10.1002/14651858.CD005101.pub4.

www.cochranelibrary.com 
TABLE OF CONTENTS

ABSTRACT 1

PLAIN LANGUAGE SUMMARY

SUMMARY OF FINDINGS

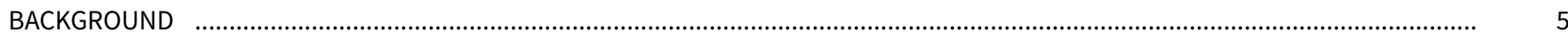

OBJECTIVES

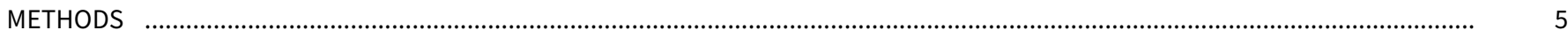

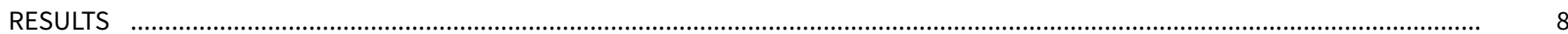

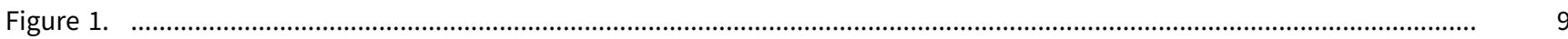

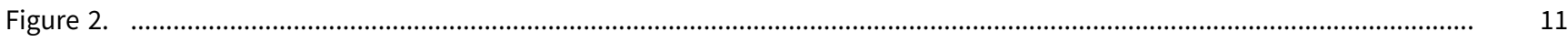

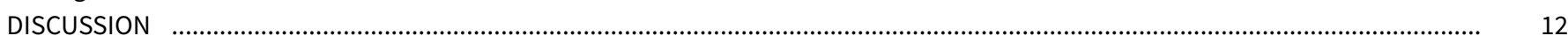

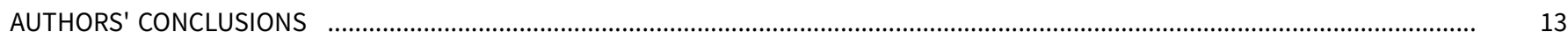

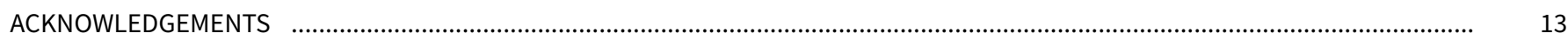

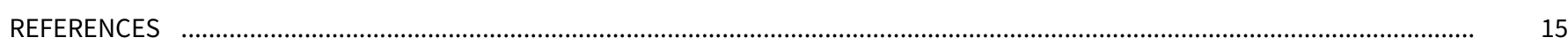

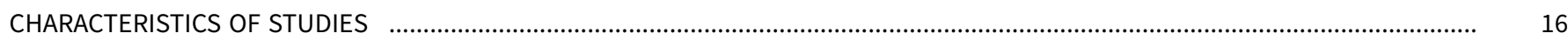

DATA AND ANALYSES

Analysis 1.1. Comparison 1 Slow-release fluoride device versus control, Outcome 1 Change of caries (increase in decayed, 19 missing, and filled permanent teeth (DMFT)) at 2 years compared to baseline.

Analysis 1.2. Comparison 1 Slow-release fluoride device versus control, Outcome 2 Change of caries (increase in decayed, 19 missing, and filled permanent surfaces (DMFS)) at 2 years compared to baseline. APPENDICES

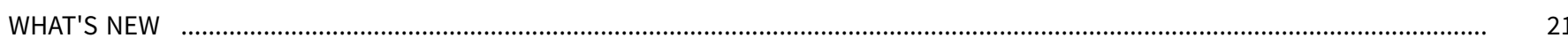

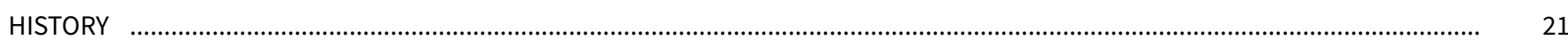

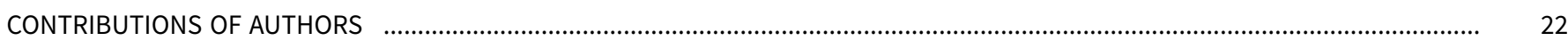

DECLARATIONS OF INTEREST

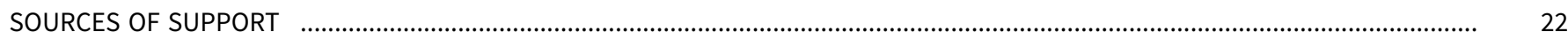

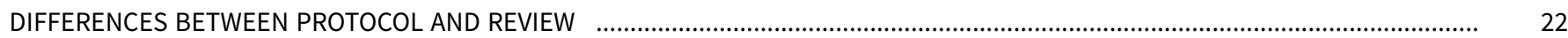

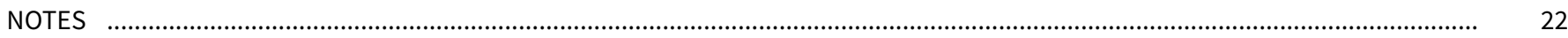

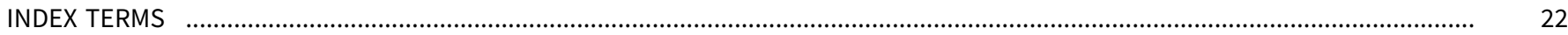


[Intervention Review]

\section{Slow-release fluoride devices for the control of dental decay}

Lee-Yee Chong ${ }^{1}$, Janet E Clarkson² ${ }^{2}$ Lorna Dobbyn-Ross ${ }^{3}$, Smriti Bhakta4

1UK Cochrane Centre, Oxford, UK. 2Division of Oral Health Sciences, University of Dundee, Dundee, UK. ${ }^{3}$ College of Medicine, Dentistry \& Nursing, University of Dundee, Dundee, UK. ${ }^{4}$ Morley Dental Centre, Leeds, UK

Contact: Janet E Clarkson, Division of Oral Health Sciences, University of Dundee, Dental Hospital \& School, Park Place, Dundee, Scotland, DD1 4HR, UK. j.e.clarkson@dundee.ac.uk.

Editorial group: Cochrane Oral Health Group.

Publication status and date: Stable (no update expected for reasons given in 'What's new'), published in Issue 4, 2018.

Citation: Chong LY, Clarkson JE, Dobbyn-Ross L, Bhakta S. Slow-release fluoride devices for the control of dental decay. Cochrane Database of Systematic Reviews 2018, Issue 3. Art. No.: CD005101. DOI: 10.1002/14651858.CD005101.pub4.

Copyright @ 2018 The Cochrane Collaboration. Published by John Wiley \& Sons, Ltd.

\section{A B S T R A C T}

\section{Background}

Slow-release fluoride devices have been investigated as a potentially cost-effective method of reducing dental caries in people with high risk of disease. This is the second update of the Cochrane Review first published in 2006 and previously updated in 2014.

\section{Objectives}

To evaluate the effectiveness and safety of different types of slow-release fluoride devices on preventing, arresting, or reversing the progression of carious lesions on all surface types of primary (deciduous) and permanent teeth.

\section{Search methods}

Cochrane Oral Health's Information Specialist searched the following electronic databases: Cochrane Oral Health's Trials Register (to 23 January 2018); the Cochrane Central Register of Controlled Trials (CENTRAL; 2017, Issue 12) in the Cochrane Library (searched 23 January 2018); MEDLINE Ovid (1946 to 23 January 2018); and Embase Ovid (1980 to 23 January 2018). The US National Institutes of Health Ongoing Trials Register ClinicalTrials.gov, and the World Health Organization International Clinical Trials Registry Platform were searched for ongoing trials (23 January 2018). We placed no restrictions on the language or date of publication when searching the electronic databases.

\section{Selection criteria}

Parallel randomised controlled trials (RCTs) comparing slow-release fluoride devices with an alternative fluoride treatment, placebo, or no intervention in all age groups. The main outcome measures sought were changes in numbers of decayed, missing, and filled teeth or surfaces (DMFT/DMFS in permanent teeth or $\mathrm{dmft} / \mathrm{dmfs}$ in primary teeth), and progression of carious lesions through enamel and into dentine.

\section{Data collection and analysis}

We conducted data collection and analysis using standard Cochrane review methods. At least two review authors independently performed all the key steps in the review such as screening of abstracts, application of inclusion criteria, data extraction, and risk of bias assessment. We resolved discrepancies through discussions or arbitration by a third or fourth review author.

\section{Main results}

We found no evidence comparing slow-release fluoride devices against other types of fluoride therapy.

We found only one double-blind RCT involving 174 children comparing a slow-release fluoride device (glass beads with fluoride were attached to buccal surfaces of right maxillary first permanent molar teeth) against control (glass beads without fluoride were attached 
to buccal surfaces of right maxillary first permanent molar teeth). This study was assessed to be at high risk of bias. The study recruited children from seven schools in an area of deprivation that had low levels of fluoride in the water. The mean age at the beginning of the study was 8.8 years and at the termination was 10.9 years. DMFT in permanent teeth or $\mathrm{dmft}$ in primary teeth was greater than one at the start of the study and greater than one million colony-forming units of Streptococcus mutans per millilitre of saliva.

Although 132 children were still included in the trial at the two-year completion point, examination and statistical analysis was performed on only the 63 children (31 in intervention group, 32 in control group) who had retained the beads (retention rate was $47.7 \%$ at 2 years). Among these 63 children, caries increment was reported to be statistically significantly lower in the intervention group than in the control group (DMFT: mean difference $-0.72,95 \%$ confidence interval $(\mathrm{Cl})-1.23$ to -0.21 ; DMFS: mean difference $-1.52,95 \% \mathrm{Cl}-2.68$ to -0.36 (very low-quality evidence)). Although this difference was clinically significant, it only holds true for those children who maintain the fluoride beads; over $50 \%$ of children did not retain the beads.

Harms were not reported within the trial report. Evidence for other outcomes sought in this review (progression to of caries lesion, dental pain, healthcare utilisation data) were also not reported.

\section{Authors' conclusions}

There is insufficient evidence to determine the caries-inhibiting effect of slow-release fluoride glass beads. The body of evidence available is of very low quality and there is a potential overestimation of benefit to the average child. The applicability of the findings to the wider population is unclear; the study had included children from a deprived area that had low levels of fluoride in drinking water, and were considered at high risk of caries. In addition, the evidence was only obtained from children who still had the bead attached at 2 years ( $48 \%$ of all available children); children who had lost their slow-release fluoride devices earlier might not have benefited as much from the devices.

\section{PLAIN LANGUAGE SUMMARY}

\section{Slow-release fluoride devices for the control of dental decay}

\section{Review question}

We conducted this review to assess the effects of different types of slow-release fluoride devices on preventing, stopping, or reversing the progression of tooth decay on all surface types of deciduous ('baby') and permanent teeth.

\section{Background}

Tooth decay is not distributed evenly among the population, with certain groups being at greater risk of developing tooth decay than others. For example, research in Scotland has shown that $50 \%$ of tooth decay occurs in $11 \%$ of 5 -year-old children and only $6 \%$ of 14 -yearold children. In light of this uneven distribution, it is often suggested that these small percentages of children may be offered targetedcaries preventive measures to great potential effect, in a cost effective manner. One such preventive measure is the use of slow-release fluoride devices (e.g. slow-dissolving fluoride-releasing glass beads).

\section{Study characteristics}

Authors from Cochrane Oral Health carried out this review of existing studies and the evidence is current up to 23 January 2018 . We searched scientific databases for clinical trials in children or adults treated with slow-release fluoride devices compared with another type of fluoride treatment (e.g. toothpaste, mouthrinse, gel, or varnish), placebo (a pretend treatment), or no treatment (usual care). Treatments had to be used and monitored for a minimum of 1 year.

\section{Key results}

We found one study that randomised 174 children to either slow-dissolving, fluoride-releasing glass beads or placebo beads. The setting was an inner city school in an area served with low-fluoride water. Only $48 \%$ of children retained the beads and were available for analysis.

There is insufficient evidence to determine whether slow-release fluoride devices (such as glass beads) help reduce dental decay. Retention of the beads is a problem.

\section{Quality of the evidence}

The evidence relating caries increment, side effects and retention was considered to be very low quality. 
SUMMARY OF FINDINGS

Summary of findings for the main comparison. Slow-release fluoride devices compared with control for the control of dental decay

Slow-release fluoride devices compared with control for the control of dental decay

Patient or population: children with high risk of dental decay

Settings: low water fluoride level area, inner city school

Intervention: slow-release fluoride devices

Comparison: control

\begin{tabular}{|c|c|c|c|c|c|c|}
\hline \multirow[t]{3}{*}{ Outcomes } & \multicolumn{2}{|c|}{$\begin{array}{l}\text { Illustrative comparative risks }{ }^{*}(95 \% \\
\mathrm{Cl})\end{array}$} & \multirow[t]{3}{*}{$\begin{array}{l}\text { Relative effect } \\
(95 \% \mathrm{CI})\end{array}$} & \multirow{3}{*}{$\begin{array}{l}\text { Number of par- } \\
\text { ticipants } \\
\text { (studies) }\end{array}$} & \multirow{3}{*}{$\begin{array}{l}\text { Quality of the } \\
\text { evidence } \\
\text { (GRADE) }\end{array}$} & \multirow[t]{3}{*}{ Comments } \\
\hline & Assumed risk & $\begin{array}{l}\text { Corresponding } \\
\text { risk }\end{array}$ & & & & \\
\hline & Control & $\begin{array}{l}\text { Slow-release fluo- } \\
\text { ride device }\end{array}$ & & & & \\
\hline $\begin{array}{l}\text { Increase in DMFS at } 2 \text { years compared } \\
\text { with baseline } \\
\text { (DMFS scale ranged from } 0 \text { to } 128 \text { ) }\end{array}$ & $\begin{array}{l}\text { The mean was } \\
1.81 \text { (SD 3.28) }\end{array}$ & $\begin{array}{l}\text { The mean was } \\
1.52 \text { lower }(95 \% \mathrm{Cl} \\
-2.68 \text { to }-0.36)\end{array}$ & Not applicable & 63 (1 study) & $\begin{array}{l}\oplus \odot \odot \ominus \\
\text { very low } \mathbf{1}\end{array}$ & - \\
\hline Dental pain due to decay & & - & - & - & - & No evidence found \\
\hline Harms of slow-release fluoride devices & - & - & - & 132 (1 study) & $\begin{array}{l}\oplus \odot \odot \odot \\
\text { very low } \mathbf{1}, \mathbf{2}\end{array}$ & $\begin{array}{l}\text { Study reported that no ir- } \\
\text { ritations or other harms } \\
\text { were reported }\end{array}$ \\
\hline Participant satisfaction & - & - & - & - & - & No RCT evidence found \\
\hline
\end{tabular}


${ }^{*}$ As there was only 1 included study, the mean values in the control group was used as the assumed risk. The corresponding risk (and its $95 \%$ confidence interval) is based on the assumed risk in the comparison group and the relative effect of the intervention (and its $95 \% \mathrm{Cl}$ ).

CI: confidence interval; DMFT: decayed, missing, and filled permanent teeth; DMFS: decayed, missing, and filled permanent surfaces; RCT: randomised controlled trial; SD: standard deviation.

GRADE Working Group grades of evidence

High quality: further research is very unlikely to change our confidence in the estimate of effect.

Moderate quality: further research is likely to have an important impact on our confidence in the estimate of effect and may change the estimate.

Low quality: further research is very likely to have an important impact on our confidence in the estimate of effect and is likely to change the estimate.

Very low quality: we are very uncertain about the estimate.

${ }^{1}$ Quality of the evidence was affected by serious attrition bias (only $36 \%$ of participants randomised were included in analysis), relatively small overall sample size and evidence was only obtained from a specific group of participants (children with high risk of caries, in an area with low levels of fluoride in tap water).

2 Unclear how reports about harms were obtained. No suggestions from the report that these were systematically checked. 


\section{B A C K G R O U N D}

\section{Description of the condition}

Dental decay is not distributed evenly among the population. For example, in epidemiological surveys in Scotland, $50 \%$ of the disease can be accounted for by including only $11 \%$ of 5 -year-old children and only $6 \%$ of 14 -year-old children (DHSRU 2003; Pitts 1999). In light of this uneven distribution, it is often advocated that these small percentages of children may be offered targeted caries preventive measures to great potential effect, in a costeffective manner. However, some dentists have cautioned that such targeted interventions may fail to effect real change if they require the targeted individuals to adopt different social norms from their peers (Batchelor 2002).

\section{Description of the intervention}

Fluoride is valuable not only in the prevention of caries but also in reversal and remineralisation of lesions (Biesbrock 1998). However, this would appear to be a slow process requiring the presence of fluoride in the mouth for extended periods of time (Rolla 1990), and the low concentrations found after brushing with fluoridecontaining dentifrice may not be sufficient to reduce the dissolution of tooth mineral significantly (ten Cate 1999).

There are a number of methods of delivering supplemental fluoride, including tablets, mouthrinses, fluoridated salt, toothpastes, gels, and varnishes. Several of these have been the subject of Cochrane Reviews (Marinho 2003; Marinho 2013; Marinho 2015; Marinho 2016; Walsh 2010). A number of devices have been used to provide a slow-released, more sustained presence of fluoride within the buccal cavity showing that it is possible to sustain elevated levels of fluoride within saliva and plaque (Mirth 1982).

\section{How the intervention might work}

The desired properties of fluoride-releasing devices include being safe to administer, providing low and continuous intraoral fluoride concentration of at least 1 year, being quick and easy to administer, being robust and being clinically effective (Toumba 2001). In terms of the desired properties of fluoride-releasing devices, only glass ionomer cements meet the criterion of long-term fluoride release of at least 1 year. Two types of intraoral fluoride slow-release device are currently in use, the co-polymer membrane (Cowsar 1976), and slow-dissolving fluoride glass beads (Toumba 1993). The glass beads, which are $4 \mathrm{~mm}$ in diameter, are attached to the buccal aspect of molar teeth using an acid-etch composite. The percentage of incorporated fluoride can be adjusted to vary the amount released and the beads have been shown to lead to raised salivary fluoride levels for up to 2 years (Toumba 1993).

\section{Why it is important to do this review}

Concerns that accidental swallowing of fluoride-containing devices might lead to gastric irritation or adverse effects following raised plasma fluoride concentrations were addressed in a study reported in 1994 (Curzon 2004). Glass beads constituted with 13.3\% fluoride were deliberately swallowed by five adult volunteers and their venous blood was subsequently drawn and analysed at intervals. Plasma fluoride concentration did not rise from baseline during 2 hours of monitoring in contrast to fluoride tablets, which gave a detectable increase peaking after 20 to 30 minutes. Based on this finding, the authors concluded that fluoride released from slowdissolving glass did not present a health risk.

The purpose of this review was to determine, if possible, the clinical effectiveness of slow-release fluoride devices for halting, or slowing, the progression of enamel, dentine, and carious root lesions on different tooth surfaces of primary (deciduous) and permanent teeth. It is anticipated that if such slow-fluoride releasing devices did prove to be clinically effective they would primarily be offered to children regarded as being at high risk of developing dental caries.

This is the second update of the Cochrane Review first published in 2006 and previously updated in 2014 (Bonner 2005; Bonner 2006; Chong 2014).

\section{O B JECTIVES}

To evaluate the effectiveness and safety of different types of slowrelease fluoride devices on preventing, arresting, or reversing the progression of carious lesions on all surface types of primary (deciduous) and permanent teeth.

\section{METHO D S}

\section{Criteria for considering studies for this review}

\section{Types of studies}

Parallel randomised controlled trials (RCTs) irrespective of publication status, language, or blinding. We did not include splitmouth trials because the treatment applied to one half may have contaminated the other half of the mouth.

\section{Types of participants}

Children or adults.

\section{Types of interventions}

\section{Intervention}

- Slow-release fluoride devices. (We considered all types of slowrelease fluoride device. However, currently the only substances that can release fluoride over a sufficient period are co-polymer acrylic reservoir types and slow-dissolving glass beads.)

\section{Comparison}

One or more of the following:

1. alternative fluoride treatment:

- topical fluoride in the form of toothpaste, mouthrinse, gel, or varnish at any dose, frequency, duration, or method of administration and with any of the following active agents/ingredients: sodium fluoride (NaF), sodium monofluorophosphate (SMFP), stannous fluoride (SnF), acidulated phosphate fluoride (APF), amine fluoride (amine F); or

2. placebo; or

3. no intervention or 'usual care'.

We included only studies with a minimum intervention and followup of 1 year. 


\section{Types of outcome measures}

\section{Primary outcomes}

1. Changes in decayed, missing, and filled teeth, or surfaces, or both (DMFT/DMFS in permanent teeth - $\mathrm{dmft} / \mathrm{dmfs}$ in primary teeth). We defined caries as being recorded at the dentine level of diagnosis. If caries data only reported caries at both dentine and enamel lesions combined then we used this in the analysis (see below for more information).

2. Progression of caries lesion through enamel or into dentine.

\section{Secondary outcomes}

1. Dental pain due to decay.

2. Retention of slow-release fluoride devices.

3. Harms of slow-release fluoride devices.

4. Participant satisfaction as measured by validated participant satisfaction questionnaires.

5. Use of healthcare resources, such as cost effectiveness of slowrelease fluoride devices, time taken to fit slow-release fluoride devices, and number of visits to the dentist for attention or refitting of slow-release fluoride devices.

Outcomes may have been assessed at more than one period of follow-up. If data from multiple time points were available, we analysed them as separate analyses at the 3 years' time point (short-term data, including studies reporting 2 to 3 years of followup), medium-term data (including studies with 4 to 6 years of follow-up), or long-term data (at least 7 years of follow-up).

We focused on shorter-term data, as longer-term data may be useful but may lose its reliability due to dropouts following natural loss of primary teeth in the case of children.

Different ways of assessing/reporting caries increment (change from baseline as measured by the decayed-missing-filled (DMF) index) in the trials were recorded separately and/or combined according to the components of the index chosen and units measured (DMFT/S, or DFT/S, or DT/S, or FT/S); types of tooth/ surface considered (primary/permanent teeth/surfaces, first molar teeth, approximal surfaces, etc.); state of tooth eruption considered (erupted and/or erupting teeth or surface); diagnostic thresholds used (cavitated/dentine lesions, non-cavitated/incipient lesions); methods of examination adopted (clinical or radiographical or both, other); and approaches to account or not for reversals in caries increment adopted (in a net or observed caries increment respectively). In addition, caries increment data have been recorded at all reported time periods (at various follow-ups).

As we were aware that caries increment could be reported differently in different trials, we developed a set of a priori rules to choose the primary outcome data (D(M)FS) for analysis from each study: DFS data would be chosen over DMFS data, and these would be chosen over DS or FS; data for 'all surface types combined' would be chosen over data for 'specific types' only; data for 'all erupted and erupting teeth combined' would be chosen over data for 'erupted' only, and these over data for 'erupting' only; data from 'clinical and radiological examinations combined' would be chosen over data from 'clinical' only, and these over 'radiological' only; data for dentinal/cavitated caries lesions would be chosen over data for enamel/non-cavitated lesions; net caries increment data would be chosen over crude (observed) increment data; and follow- up nearest to 3 years (often the one at the end of the treatment period) would be chosen over all other lengths of follow-up, unless otherwise stated. When no specification was provided with regard to the methods of examination adopted, diagnostic thresholds used, groups of teeth and types of tooth eruption recorded, and approaches for reversals adopted, the primary choices described above were assumed.

\section{Search methods for identification of studies}

\section{Electronic searches}

Cochrane Oral Health's Information Specialist conducted systematic searches in the following databases for randomised controlled trials and controlled clinical trials. There were no language, publication year or publication status restrictions:

- Cochrane Oral Health's Trials Register (to 23 January 2018) (Appendix 1);

- Cochrane Central Register of Controlled Trials (CENTRAL; 2017, Issue 12) in the Cochrane Library (searched 23 January 2018) (Appendix 2);

- MEDLINE Ovid (1946 to 23 January 2018) (Appendix 3);

- Embase Ovid (1980 to 23 January 2018) (Appendix 4).

Subject strategies were modelled on the search strategy designed for MEDLINE Ovid. Where appropriate, they were combined with subject strategy adaptations of the highly sensitive search strategy designed by Cochrane for identifying randomised controlled trials and controlled clinical trials as described in the Cochrane Handbook for Systematic Reviews of Interventions Chapter 6 (Lefebvre 2011).

\section{Searching other resources}

We handsearched all the references lists of the included studies to identify any additional studies.

We searched the following databases for ongoing trials (Appendix 5 for search strategies applied):

- US National Institutes of Health Ongoing Trials Register ClinicalTrials.gov (clinicaltrials.gov) (to 23 January 2018);

- World Health Organization International Clinical Trials Registry Platform (apps.who.int/trialsearch/) (to 23 January 2018).

\section{Data collection and analysis}

We used Review Manager 5 to perform every step of the review (Review Manager 2014). We assessed the risk of bias of the included studies according to the criteria described in the Cochrane Handbook for Systematic Reviews of Interventions (Higgins 2011).

\section{Selection of studies}

Two review authors independently assessed the titles and abstracts of all reports identified by the online searches on the basis of title, keywords, and abstract (when this was available) to determine if the study was likely to be relevant. We obtained the full-text report of all potentially relevant articles.

The review authors were not blinded with respect to report authors, journals, date of publication, sources of financial support, or results. Two review authors independently applied the inclusion criteria in duplicate, and compared opinions afterwards in discussion with a third review author. 


\section{Data extraction and management}

We used an itemised form to ensure consistency of data extraction between studies and between assessors. At least two review authors independently carried out the data extraction, and, in case of discrepancies, we sought consensus by discussion with a third review author.

\section{Assessment of risk of bias in included studies}

At least two review authors undertook the risk of bias assessment of included trials. We resolved any disagreements by discussion with a third review author (Jan Clarkson).

Risk of bias assessment was conducted using the standard recommended approach for assessing the risk of bias in studies included in Cochrane Reviews (Higgins 2011), and assessed the following domains:

- sequence generation;

- allocation concealment;

- blinding of participants and personnel;

- blinding of outcomes assessment;

- incomplete outcome data;

- selective outcome reporting;

- other bias.

The review authors would assign judgement on the risk of bias for each domain into either one of these categories: high, low, or unclear risk of bias. We based these assessments on the criteria for making judgement listed in the Section 8.5 of the Cochrane Handbook for Systematic Reviews of Interventions, which focuses on whether the risk is of importance (i.e. whether the presence of the risk could have an important impact the results or the conclusion of the trial) rather than whether a risk bias was present or not (Higgins 2011).

We categorised the overall risk of bias of individual studies. Studies were categorised as being at low, high, or unclear risk of bias according to the following criteria:

- low risk of bias (plausible bias unlikely to seriously alter the results) if all domains were at low risk of bias;

- high risk of bias (plausible bias that seriously weakens confidence in the results) if one or more domains were at high risk of bias; or

- unclear risk of bias (plausible bias that raises some doubt about the results) if one or more domains were at unclear risk of bias.

We also presented the 'Risk of bias' summary graphically.

\section{Measures of treatment effect}

For dichotomous outcomes (where the outcome of interest was either present or absent), the estimate of treatment effect of an intervention would have been expressed as risk ratios (RR) together with 95\% confidence intervals (Cls) or as hazard ratios if these were available as time-to-event data. For continuous outcomes (such as mean visual analogue scale (VAS) scores), we reported mean differences (MD) and standard deviation (SD).

\section{Unit of analysis issues}

For cluster-randomised trials, we estimated the design effect using the appropriate methods as detailed in Chapter 16 of the Cochrane Handbook for Systematic Reviews of Interventions (Higgins 2011).

\section{Dealing with missing data}

Where data were missing from the published report of a trial, we attempted to contact the author(s) to obtain the data and clarify any uncertainty. We based the review on an available-case analysis basis where data were missing, followed by sensitivity analysis where possible if the missing data posed a high risk of bias. For continuous data, we used methods for estimating missing SDs in Section 7.7.3 of the Cochrane Handbook for Systematic Reviews of Interventions if appropriate (Higgins 2011). Otherwise, we would not have undertaken any imputations or use any statistical methods to impute missing data.

\section{Assessment of heterogeneity}

We assessed clinical heterogeneity by examining the types of participants (e.g. age), interventions (e.g. method of restoration), and outcomes (e.g. pain relief) in each study.

We assessed heterogeneity by inspection of the point estimates and $\mathrm{Cls}$ on the forest plots. We assessed the variation in treatment effects by means of Cochran's test for heterogeneity and quantified it using the 12 statistic. We considered heterogeneity statistically significant if $P$ value was $<0.1$.

An approximate guide to interpretation provided in the Cochrane Handbook for Systematic Reviews of Interventions is as follows (Higgins 2011):

- $0 \%$ to $40 \%$ : might not be important;

- $30 \%$ to $60 \%$ : may represent moderate heterogeneity;

- $50 \%$ to $90 \%$ : may represent substantial heterogeneity;

- $75 \%$ to $100 \%$ : considerable heterogeneity.

The importance of the observed value of the 12 statistic depends on 1 ) the magnitude and direction of the effects and 2) the strength of evidence for heterogeneity (e.g. $\mathrm{P}$ value from the $\mathrm{Chi}^{2}$ test or a $\mathrm{Cl}$ for the $1^{2}$ statistic).

\section{Assessment of reporting biases}

Reporting bias could be assessed as between-study publication or within-study reporting bias.

If there had been sufficient numbers of trials (more than 10) in any meta-analysis, we would have assessed publication bias according to the recommendations on testing for funnel plot asymmetry (Egger 1997) as described in Section 10.4 of the Cochrane Handbook for Systematic Reviews of Interventions (Higgins 2011). If we had identified asymmetry, we would have examined possible causes. Alternatively, we would have assessed this using a table to list the outcomes reported by each study included to review, to identify whether there were any studies that did not report outcomes that had been reported by most studies.

We would have assessed within-study reporting bias by comparing the outcomes reported in the published report against the outcomes reported in the study protocol, whenever this could be obtained. If not, then outcomes listed in the methods section 
could be compared with those whose results were reported. If non-significant results were mentioned but were not reported adequately, bias in a meta-analysis is likely to occur and we would have sought further information from authors of the study reports. Otherwise, we would note this as 'high' risk of bias. If there was insufficient information to judge the risk of bias, we would have noted it as 'unclear' risk of bias.

\section{Data synthesis}

For data analysis, we were guided by the Cochrane Handbook for Systematic Reviews of Interventions (Higgins 2011). For the continuous outcome measures analysed in this review, we used means and SDs to summarise the data for each group. We would have used standardised mean difference (SMD) as a summary statistic in meta-analysis when the studies all assessed the same outcome but measured it in a variety of ways.

For dichotomous data, the estimate of effect of an intervention would have been expressed as RRs, together with $95 \% \mathrm{Cls}$ or as hazard ratios if these were reported as time-to-event data.

We would have used a random-effects model to pool effect estimates provided it was appropriate to pool the data (as assessed by clinical and statistical heterogeneity).

\section{Subgroup analysis and investigation of heterogeneity}

Where data were available, we would have conducted subgroup analyses to investigate the effects of the following factors: different tooth surfaces (enamel, dentine, and root surface), amount of fluoride released and duration of exposure, adults/children, or length of follow-up.

\section{Sensitivity analysis}

We conducted sensitivity analysis based on risk of bias where applicable.

\section{Presentation of main results}

We developed a 'Summary of findings' table for each comparison and for the main outcomes of this review following GRADE methods (GRADE 2004). The quality of the body of evidence was assessed with reference to the overall risk of bias of the included study, the directness of the evidence, the inconsistency of the results, the precision of the estimates, and the risk of publication bias. We categorised the quality of the body of evidence of each of the main outcomes as high, moderate, low or very low.

\section{RES U L T S}

\section{Description of studies}

\section{Results of the search}

Initial searches of all sources yielded 73 titles and abstracts, we found an additional 324 records in the 2014 update, and 29 in this latest update. In total, 426 records have been assessed for eligibility. We obtained the full texts of seven papers as being potentially relevant to this review. Two of the seven papers described the same study, which met the inclusion criteria for the review (Toumba 2005). We excluded the remaining five studies and provided details in the Characteristics of excluded studies table. See Figure 1. 
Figure 1. Study flow diagram.

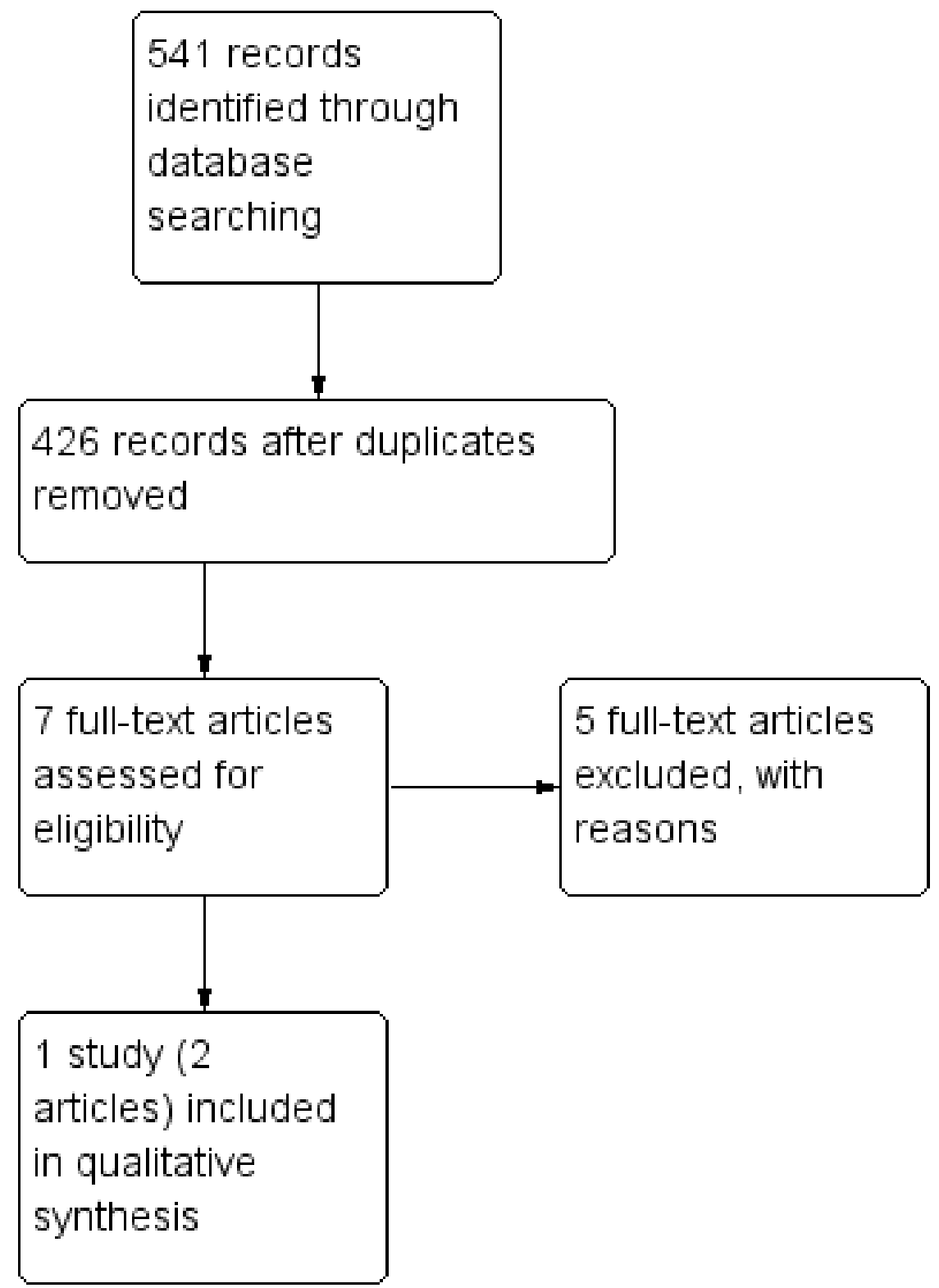

\section{Included studies}

Summary details are provided in the Characteristics of included studies table. Only one study met the inclusion criteria of the review (Toumba 2005).

\section{Participants and setting}

Toumba 2005 was conducted exclusively in an area of deprivation in an inner-city area of Leeds, UK (postcode LS11). All examinations and placement of devices were by one investigator and utilised portable dental equipment set up in seven primary schools in Beeston, Leeds.

Children had a mean age of 8.8 years at the beginning of the study and 10.9 years at the termination. Number of DMFT in permanent teeth or dmft in primary teeth were greater than one at the start of the study and there were greater than one million colony-forming units of Streptococcus mutans per millilitre of saliva.

\section{Intervention}

Glass beads were attached to buccal surfaces of right maxillary first permanent molar teeth. In the intervention group, glass beads were constituted with fluoride that was designed to be released slowly as the glass dissolved in the mouth.

\section{Control}

Glass beads were manufactured without fluoride and attached to buccal surfaces of right maxillary first permanent molar teeth.

\section{Outcomes}

Only one of the outcomes of interest to this review was reported in this study; changes in decayed-missing-filled dmf (DMF). Comparisons were made between scores for DMF/dmf teeth and surfaces ( $\mathrm{dmft} / \mathrm{dmfs}$ in primary teeth, DMFT/DMFS in permanent teeth) in intervention and control groups at baseline, mid-study, 
and at termination (2 years). At the end of the study period, caries increments were compared separately and combined for DMF/dmf and DMFS/dmfs, and also specifically on occlusal surfaces.

\section{Excluded studies}

A summary is provided in the Characteristics of excluded studies table.
We excluded five potentially relevant studies on the grounds of not being randomised controlled trials (Aaltonen 2000; De Los Santos 1994), inadequate randomisation (Marini 1999; Trimpeneers 1996), being a split-mouth study (Trimpeneers 1996), or inappropriate intervention (Cagetti 2014).

\section{Risk of bias in included studies}

We assessed the included study as at high risk of bias. See Figure 2. 
Figure 2. Risk of bias summary: review authors' judgements about each risk of bias item for each included study.

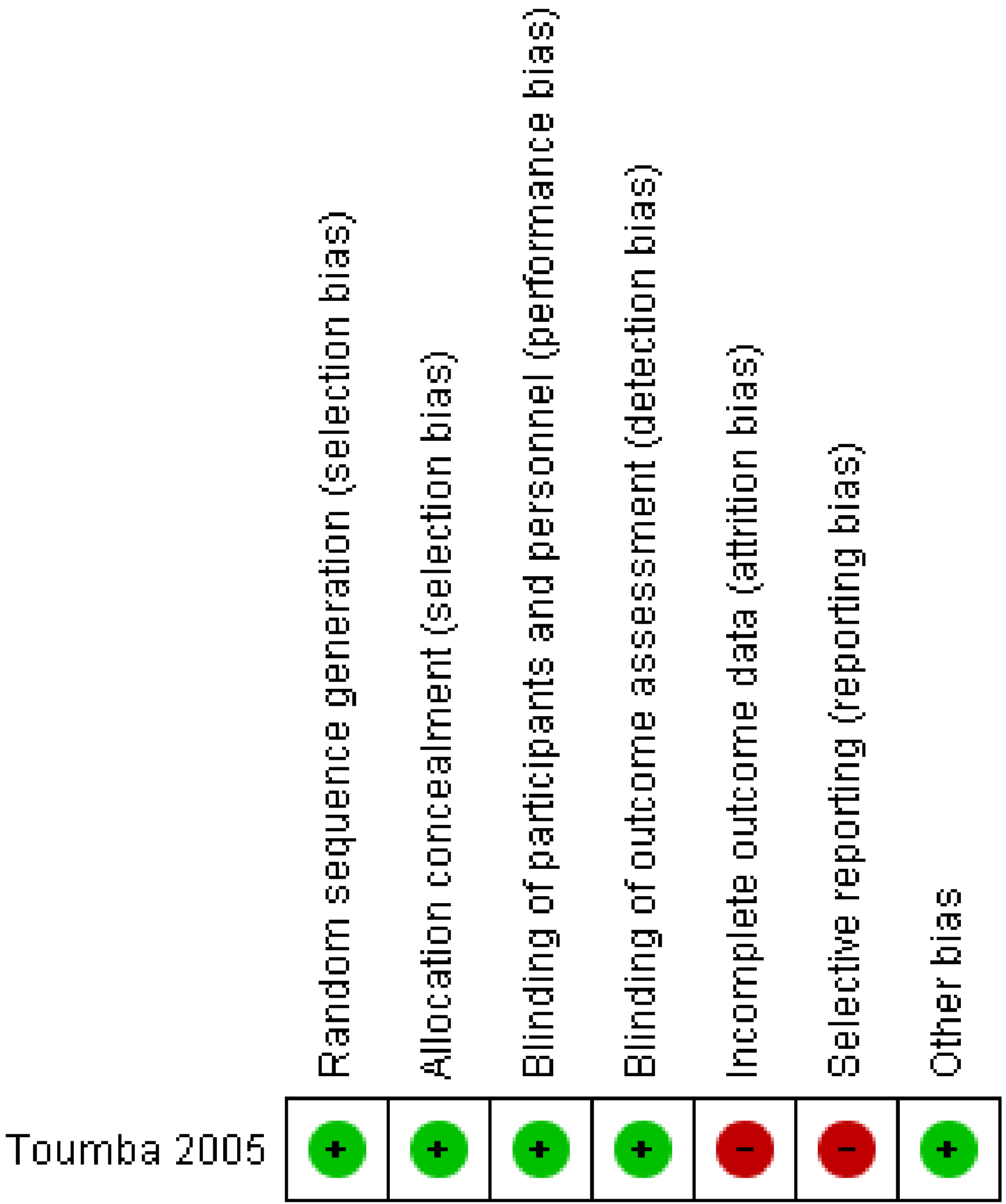

\section{Allocation}

The methods of randomisation and concealment of allocation were clearly explained and were adequate to guard against bias.

\section{Blinding}

The control group participants were fitted with glass beads of identical appearance to those fitted to the intervention arm, with similar proportions of dislodgement. We also have been assured 
that the examiner remained blinded to the study group until the final examinations had been carried out.

\section{Incomplete outcome data}

Of concern was the high level of attrition in participant number. The acknowledged number of dropouts was a modest 15; however, only 63 of the original 174 children were included in the final analysis. Children whose beads had dislodged were not assessed for dental disease within the study. The total loss to follow-up was thus $64 \%$. Although the control ( 32 children) and intervention (31 children) groups held similar numbers at the end of study assessment, the review authors considered that the validity of an extrapolation, from this trial to any potential use of this technique in the prevention of caries in practice, requires analysis to be based on all participants. Therefore, we consider that there is a high risk of bias.

\section{Selective reporting}

The protocol stated that outcomes were measured at 6 months, 12 months, and 2 years, but only data for 2 years among participants who still had the slow-release fluoride devices intact were reported.

\section{Other potential sources of bias}

We identified no other potential sources of bias.

\section{Effects of interventions}

See: Summary of findings for the main comparison Slow-release fluoride devices compared with control for the control of dental decay

\section{Comparison of slow-release fluoride device versus placebo or usual care}

Number of decayed, missing, and filled teeth, or surfaces (DMFT) S), or both

One hundred and thirty-two out of 174 children recruited to the study were still included at 2 years, but only 63 children still had beads attached. Those 63 children alone were included in the comparisons ( 31 intervention and 32 control).

Caries increment was significantly lower in the intervention group than in the control group (mean difference (MD) - 0.72 DMFT, 95\% confidence interval $(\mathrm{Cl})-1.23$ to -0.21 ; MD -1.52 DMFS, $95 \% \mathrm{Cl}-2.68$ to -0.36$)$.

Clinical assessment of dmft and dmfs was also reported in this study (Toumba 2005). However, we did not consider the data to be usable as it was unclear how the quoted mean caries increment for $\mathrm{dmft} / \mathrm{dmfs}$ over the 2 years related to the values given at the three time points and the study authors were unable to provide clarification. In addition, we could not obtain information regarding caries experience of the $52 \%$ of participants not included in the analysis.

\section{Progression of caries lesion through enamel or into dentine}

The study reported no data on progression of caries lesion through enamel or into dentine.

\section{Dental pain}

The study reported no data on dental pain.

\section{Harms of slow-release fluoride devices}

Harms were not measured or formally reported within the trial report.

The study stated that "Despite this loss the devices were well tolerated by the children and there were no reports of irritation etc".

\section{Participant satisfaction}

The study reported no data on participant satisfaction.

\section{Retention of slow-release fluoride devices}

Out of 174 children recruited into the trial, only 132 completed the study. Of these, 31 in the intervention group and 32 in the control group still had the devices intact, with an overall 63/132 (47.8\%) retention of devices after 2 years. The devices used for both groups appeared to be the same, except that the devices in the intervention group contained fluoride.

Use of healthcare resources (e.g. cost effectiveness, time taken to fit, number of visits to the dentist for attention, or re-fitting of slow-release fluoride devices)

The study reported no data on use of healthcare resources.

Comparison of slow-release fluoride device versus alternative fluoride therapy

We found no studies comparing a slow-release fluoride device versus alternative fluoride therapy.

\section{DISCUSSION}

\section{Summary of main results}

Evidence from one small randomised controlled trial among primary school children in an area with low fluoride levels in drinking water suggested that slow-release fluoride may reduce the incidence of caries. However, this could be an overestimation, as the results only reported the outcomes among children who retained the devices at 2-year follow-up. The devices were intact in less than half (47.7\%) of all participants followed up at 2 years.

\section{Overall completeness and applicability of evidence}

Although several slow-release fluoride devices have been devised, the lack of well-controlled studies into the effectiveness of these is disappointing.

The study accepted for this review provided some evidence for a reduction in dental disease progression in high-risk children. Although relatively long-term evidence at 2 years was available, this was obtained from a relatively small trial and data were only obtained from $36 \%$ of the randomised children ( 63 children out of 174 randomised). The exclusion of the majority of children from the statistical analysis posed a significant risk of attrition bias, as the effectiveness of caries prevention may have been lessened in the children who lost the devices at an earlier date (Newell 1992). This trial also randomised a specific population of participants; that is, children attending schools in the inner city of Leeds, UK (disadvantaged backgrounds).

Only two outcomes of interest were reported; DMFT/DMFS and retention of slow-release fluoride devices at the end of 2 years, with no data reported about other aspects of potential benefit, harms, 
participant satisfaction, and cost effectiveness of the intervention. Participant harm was not measured or discussed within the trial report, resulting in an incomplete measure of potential of harms and benefits from the devices (Toumba 2005).

\section{Quality of the evidence}

We graded the quality of the evidence obtained as very low using GRADE. Our confidence in the evidence was affected by serious study limitations (high risk of bias from attrition/selective reporting), potential limitations in applicability of the results to the wider population, and an overall small number of participants included. Furthermore, there was lack of completeness in the overview of balance of benefits and harms data as potential adverse effects were not reported.

\section{Potential biases in the review process}

We have not identified any potential biases in the review process, as all data extractions and study inclusion/exclusion were conducted as planned.

\section{Agreements and disagreements with other studies or reviews}

The included study did not measure or reported any harms from the devices.

Slow-dissolving glass beads similar to those used in the included study are used commercially to deliver mineral supplements in livestock. Since the adaptation of these devices for dental purpose in humans, the same study authors have tested, in a limited way, the potential effect of swallowing fluoride-containing slowdissolving beads on enteric absorption of fluoride (Curzon 2004). Plasma fluoride concentration did not rise from baseline during 2 hours of monitoring in contrast to fluoride tablets, which gave a detectable increase peaking after 20 minutes to 30 minutes. From this result, they concluded that fluoride released from slowdissolving glass does not present a health risk.

The included study involved a limited number of children from a defined high-risk population and points the way towards the need for a larger, more general, trial. The question of retention of the devices in place also needs to be addressed. For orthodontic brackets, overall bonding failure rate was found to be $8 \%$ but three times greater in children under the age of 12 years (Millett 1994). The discussion section of the included study report indicated there was a particular problem with children deliberately setting out to dislodge their bonded glass beads, but that improvements in bonding techniques are already being explored (Toumba 2005). These include the factoring of a retention groove around the periphery of the bead, which, it is claimed, improves retention (Welbury 2003).

\section{AUTHORS' CONCLUSIONS}

\section{Implications for practice}

We conclude that there is only limited and very low-quality evidence that provides insufficient information to determine whether slow-release fluoride devices in the mouth may provide a measure of protection against dental disease progression (Toumba 2005). The quality of the evidence was very low because of a high proportion of children not included in the study's final analysis and serious uncertainty applicability of study findings to the general practice. The generalisability of these findings to routine dental practice was questioned by the difficulties of retention of the devices by the study population (children at high risk of caries, living in an area with low levels of fluoride in tap water). Clearly, once the beads have been dislodged they are no longer useful. In addition, the beneficial effects seen might prescribe careful selection of the target recipients to be cost-effective.

\section{Implications for research}

- Evidence: the study identified for this review did not provide reliable evidence to answer the main question of the review. Some limited evidence was found but weaknesses in this were evident. To remedy these weaknesses, much larger, well-conducted trials (randomised controlled trials, and where possible, double-blinded) should be carried out. These trials should, perhaps, draw comparisons between available alternatives such as gels or varnishes and should provide analysis of results on the basis of intention-to-treat and consider costs and benefits. One of the authors of the included study has previously concluded that the use of slow fluoride-releasing glass beads is a cost-effective technique (Toumba 1997). The included study focused on children from a low socio-economic area (Toumba 2005). It may also be of benefit to establish how much fluoride should be released from the devices for optimum effect. Different materials and methods used for bonding may influence the efficacy of fluoride release as well as the strength of the bonding.

- Population: participants from different risk categories.

- Intervention: slow-release fluoride devices, of different materials or methods for bonding.

- Comparison: placebo or other slow-release fluoride devices of a different material or methods of bonding, or amount of fluoride released.

- Outcomes:

- primary outcomes:

i. number of decayed, missing, and filled teeth or surfaces or both (DMFT/DMFS in permanent teeth - $\mathrm{dmft} / \mathrm{dmfs}$ in primary teeth);

ii. progression of caries lesion through enamel or into dentine;

- secondary outcomes:

i. dental pain;

ii. harms of slow-release fluoride devices, including adverse effects of swallowing dislodged devices;

iii. participant satisfaction;

iv. retention of devices (number of devices staying intact);

v. other healthcare utilisation data (e.g. time taken to fit, number of visits to the dentist for attention to or re-fitting of slow-release fluoride devices and cost effectiveness of the slow-release fluoride devices).

- Time: the intervention and follow-up should be conducted for a minimum of 1 year, and preferable for a longer duration.

\section{ACKNOWLEDGEMENTS}

We wish to acknowledge the help of Anne Littlewood, Information Specialist, in the design of the search strategy and of Luisa Fernandez Mauleffinch, Managing Editor, and the rest of the Cochrane Oral Health editorial team. We thank referees for 
providing comments and Brian Bonner for his contribution to earlier versions of this review. 
R E F E R E N C E S

\section{References to studies included in this review}

Toumba 2005 \{published data only\}

Toumba KJ. Slow-release devices for fluoride delivery to highrisk individuals. Caries Research 2001;35 Suppl 1:10-3.

* Toumba KJ, Curzon ME. A clinical trial of a slow-releasing fluoride device in children. Caries Research 2005;39(3):195-200. [DOI:10.1159/000084798]

\section{References to studies excluded from this review}

Aaltonen 2000 \{published data only\}

Aaltonen AS, Suhonen JT, Tenovuo J, Inkila-Saari I. Efficacy of a slow-release device containing fluoride, xylitol and sorbitol in preventing infant caries. Acta Odontologica Scandinavica 2000;58(6):285-92.

\section{Cagetti 2014 \{published data only\}}

Cagetti MG, Carta G, Cocco F, Sale S, Congiu G, Mura A, et al. Effect of fluoridated sealants on adjacent tooth surfaces: a 30-mo randomized clinical trial. Journal of Dental Research 2014;93(7 Suppl 1):59S-65S. [DOI: 10.1177/0022034514535808]

De Los Santos 1994 \{published data only\}

De Los Santos R, Lin YT, Corpron RE, Beltran ED, Strachan DS, Landry PA. In situ remineralization of root surface lesions using a fluoride chewing gum or fluoride-releasing device. Caries Research 1994;28(6):441-6.

\section{Marini 1999 \{published data only\}}

Marini I, Pelliccioni GA, Vecchiet F, Alessandri Bonetti G, Checchi L. A retentive system for intra-oral fluoride release during orthodontic treatment. European Journal of Orthodontics 1999;21(6):695-701.

\section{Trimpeneers 1996 \{published data only\}}

Trimpeneers LM, Dermaut LR. A clinical evaluation of the effectiveness of a fluoride-releasing visible light-activated bonding system to reduce demineralization around orthodontic brackets. American Journal of Orthodontics and Dentofacial Orthopedics 1996;110(2):218-22.

\section{Additional references}

\section{Batchelor 2002}

Batchelor P, Sheiham A. The limitations of a 'high risk' approach for the prevention of dental caries. Community Dentistry and Oral Epidemiology 2002;30(4):302-12.

\section{Biesbrock 1998}

Biesbrock AR, Faller RV, Bartizek RD, Court LK, McClanahan SF. Reversal of incipient and radiographic caries through the use of sodium and stannous fluoride dentifrices in a clinical trial. Journal of Clinical Dentistry 1998;9(1):5-10.

\section{Cowsar 1976}

Cowsar D, Tarwater O, Tanquary A. Controlled release of fluoride from hydrogels for dental applications. In: Andrade JD editor(s). Hydrogels for Medical and Related Applications. Vol. 31, Washington: American Chemical Society, 1976:180-97.

\section{Curzon 2004}

Curzon ME, Toumba KJ. In vitro and in vivo assessment of a glass slow fluoride releasing device: a pilot study. British Dental Journal 2004;196(9):543-6.

\section{DHSRU 2003}

Dental Health Services Research Unit. Scotland's National Dental Inspection Programme. Dundee: Scottish Dental, 2003.

\section{Egger 1997}

Egger M, Davey Smith G, Schneider M, Minder C. Bias in meta-analysis detected by a simple, graphical test. $B M J$ 1997;315:629-34.

\section{GRADE 2004}

Atkins D, Best D, Briss PA, Eccles M, Falck-Ytter Y, Flottorp S, et al. Grading quality of evidence and strength of recommendations. BMJ 2004;328(7454):1490.

\section{Higgins 2011}

Higgins JP, Green S, editor(s). Cochrane Handbook for Systematic Reviews of Interventions Version 5.1.0 (updated March 2011). The Cochrane Collaboration, 2011. Available from www.handbook.cochrane.org.

\section{Marinho 2003}

Marinho VCC, Higgins J, Logan S, Sheiham A (deceased). Fluoride toothpastes for preventing dental caries in children and adolescents. Cochrane Database of Systematic Reviews 2003, Issue 1. [DOI: 10.1002/14651858.CD002278]

\section{Marinho 2013}

Marinho VCC, Worthington HV, Walsh T, Clarkson JE. Fluoride varnishes for preventing dental caries in children and adolescents. Cochrane Database of Systematic Reviews 2013, Issue 7. [DOI: 10.1002/14651858.CD002279.pub2]

\section{Marinho 2015}

Marinho VCC, Worthington HV, Walsh T, Chong LY. Fluoride gels for preventing dental caries in children and adolescents. Cochrane Database of Systematic Reviews 2015, Issue 6. [DOI: 10.1002/14651858.CD002280.pub2]

\section{Marinho 2016}

Marinho VCC, Chong LY, Worthington HV, Walsh T. Fluoride mouthrinses for preventing dental caries in children and adolescents. Cochrane Database of Systematic Reviews 2016, Issue 7. [DOI: 10.1002/14651858.CD002284.pub2]

\section{Millett 1994}

Millett DT, Gordon PH. A 5-year clinical review of bond failure with a no-mix adhesive (Right on). European Journal of Orthodontics 1994;16(3):203-11. 


\section{Mirth 1982}

Mirth DB, Shern RJ, Emilson CG, Adderly DD, Li SH, Gomez IM, et al. Clinical evaluation of an intraoral device for the controlled release of fluoride. Journal of the American Dental Association 1982;105(5):791-7.

\section{Newell 1992}

Newell DJ. Intention-to-treat analysis: implications for quantitative and qualitative research. International Journal of Epidemiology 1992;21(5):837-41.

\section{Pitts 1999}

Pitts NB, Nugent ZJ, Smith PA. The Scottish Health Boards' Dental Epidemiological Programme Report of the 1998/1999 survey of 14-year-old children. Dundee, UK: University of Dundee, 1999.

\section{Review Manager 2014 [Computer program]}

Nordic Cochrane Centre, The Cochrane Collaboration. Review Manager 5 (RevMan 5). Version 5.3. Copenhagen: Nordic Cochrane Centre, The Cochrane Collaboration, 2014.

\section{Rolla 1990}

Rolla G, Saxegaard E. Critical evaluation of the composition and use of topical fluorides, with emphasis on the role of calcium fluoride in caries inhibition. Journal of Dental Research 1990;69(Spec No):780-5.

\section{ten Cate 1999}

ten Cate JM. Current concepts on the theories of the mechanism of action of fluoride. Acta Odontologica Scandinavica 1999;57(6):325-9.

\section{Toumba 1993}

Toumba KJ, Curzon ME. Slow-release fluoride. Caries Research 1993;27 Suppl 1:43-6.

\section{Toumba 1997}

Toumba KJ, Curzon ME. Cost-effectiveness and benefit-cost of a slow fluoride releasing device. Journal of Dental Research 1997;76 Suppl:964.

\section{Toumba 2001}

Toumba KJ. Slow-release devices for fluoride delivery to highrisk individuals. Caries Research 2001;35 Suppl 1:10-3.

\section{Walsh 2010}

Walsh T, Worthington HV, Glenny AM, Appelbe P, Marinho VCC, Shi X. Fluoride toothpastes of different concentrations for preventing dental caries in children and adolescents. Cochrane Database of Systematic Reviews 2010, Issue 1. [DOI: 10.1002/14651858.CD007868.pub2]

\section{Welbury 2003}

Welbury R, Toumba KJ. Slow-release F. Scottish Dentist 2003;62(May-June):18-9.

\section{References to other published versions of this review Bonner 2005}

Bonner BC, Clarkson JE. Slow-release fluoride devices for the control of dental decay. Cochrane Database of Systematic Reviews 2005, Issue 1. [DOI: 10.1002/14651858.CD005101]

\section{Bonner 2006}

Bonner BC, Clarkson JE, Dobbyn L, Khanna S. Slowrelease fluoride devices for the control of dental decay. Cochrane Database of Systematic Reviews 2006, Issue 4. [DOI: 10.1002/14651858.CD005101.pub2]

\section{Chong 2014}

Chong LY, Clarkson JE, Dobbyn-Ross L, Bhakta S. Slowrelease fluoride devices for the control of dental decay. Cochrane Database of Systematic Reviews 2014, Issue 11. [DOI: 10.1002/14651858.CD005101.pub3]

* Indicates the major publication for the study

\section{CHARACTERISTICS OF STUDIES}

Characteristics of included studies [ordered by study ID]

Toumba 2005

\begin{tabular}{ll}
\hline Methods & Double-blind RCT, 2-year follow-up \\
\hline Participants & Sample: 174 children, mean age 8.8 years \\
& Dropouts: 132 children were still in the trial at the 2 -year completion point; however, only 63 had re- \\
& $\begin{array}{l}\text { tained the fitted glass beads. The baseline characteristics and outcomes data were only reported for } 63 \\
\text { children, } 31 \text { in intervention group and } 32 \text { in control group, who had retained the fitted glass beads to } \\
\text { the study end point }\end{array}$ \\
Inclusion criteria: & attended 1 of 7 schools, residing in postcode LS11 (inner city, Leeds, UK) \\
& aged 8 years old (born in 1983)
\end{tabular}


Toumba 2005 (Continued)

- $\mathrm{dmft}$ or DMFT > 1 and > 1 million Streptococcus mutans (colony-forming units)/mL saliva

- no medical contraindications

Interventions

\section{Intervention:}

- glass beads constituted with fluoride that was designed to be released slowly as the glass dissolved in the mouth

\section{Control:}

- glass beads manufactured without fluoride with identical appearance to the intervention

\section{Method of fitting (all participants):}

- glass beads were attached to buccal surfaces of right maxillary first permanent molar tooth. The tooth surface was cleaned with fluoride-free paste (washed and dried), the cleaned surface etched with 40\% phosphoric acid gel (washed and dried), and Scotchbond, light-cure bonding agent was applied thinly to both tooth surface and bead. The glass device was then attached to the tooth using Herculite, universal shade, light-curing composite resin

- 1 spare device was provided in each container and replacement was permitted, in the case of dislodgment, for up to 4 months from the start of the study

- examinations and device fitment was carried out on school premises using portable dental equipment

- Dental caries were assessed at baseline, 1 year, and 2 years
- Gingival health was measured as periodontal health, cleanliness, and presence of calculus
Outcomes reported (only for the children who completed the 2-year study with the devices still intact)
- Streptococcus mutans counts were determined at baseline, 1 year, and 2 years
- Unstimulated whole mixed saliva, taken 2 hours postprandial, was collected at the time of dental ex-
amination and analysed for fluoride concentration at baseline, 1 year, and 2 years
- DMFT/dmft
- DMFS/dmfs

\begin{tabular}{ll}
\hline Source of Funding & The trial was supported by a grant from the Wolfston Foundation \\
\hline Declaration of Interest & None declared \\
\hline Notes & Study area was 1 of social deprivation and low level of dental care. The tap water in area had less than \\
& $0.1 \mathrm{mg} / \mathrm{L}$ of fluoride and dental caries were among the highest in the UK
\end{tabular}

\section{Risk of bias}

\begin{tabular}{lll}
\hline Bias & Authors' judgement & Support for judgement \\
\hline $\begin{array}{l}\text { Random sequence genera- } \\
\text { tion (selection bias) }\end{array}$ & Low risk & Random number tables were used to generate sequence \\
\hline $\begin{array}{l}\text { Allocation concealment } \\
\text { (selection bias) }\end{array}$ & Low risk & $\begin{array}{l}\text { Glass beads were in containers in plastic bags coded by a third party and num- } \\
\text { bered using the random number table. Codes were kept in a safe until end of } \\
\text { study }\end{array}$ \\
\hline $\begin{array}{l}\text { Blinding of participants } \\
\text { and personnel (perfor- } \\
\text { mance bias) }\end{array}$ & Low risk & $\begin{array}{l}\text { "Because both the control and test glass pellets were identical in shape and } \\
\text { appearance the examiner could not know which device was in place in each } \\
\text { child's mouth. The glass devices were coded by an independent investigator } \\
\text { not involved in the clinical trial to avoid any bias. The glass samples for the de- } \\
\text { vices were supplied by the manufacturer and were of two types, the test and } \\
\text { control glass devices. The control glass device contained no } F \text { [fluoride] at all, } \\
\text { but was identical in every other aspect including appearance" }\end{array}$
\end{tabular}


Participants in control and intervention groups were fitted with glass bead devices of identical appearance. Glass beads were in containers coded by a third party (using a random numbers table) and neither the investigator nor the participants were aware of which type was fitted to each individual

All examinations and device placement was by 1 investigator who demonstrated his reliability of assessments (Kappa 0.86 for caries and 0.76 for periodontal indices) on a group of 25 children

\begin{tabular}{lll}
\hline $\begin{array}{l}\text { Blinding of outcome as- } \\
\text { sessment (detection bias) } \\
\text { All outcomes }\end{array}$ & Low risk & Likely to be low risk; identical appearance of beads \\
\hline $\begin{array}{l}\text { Incomplete outcome data } \\
\text { (attrition bias) } \\
\text { All outcomes }\end{array}$ & High risk & $\begin{array}{l}\text { Outcome was only available for } 63 \text { out of } 174 \text { children randomised (36\%). Only } \\
\text { children who retained the beads were included in the analysis }\end{array}$ \\
\hline $\begin{array}{l}\text { Selective reporting (re- } \\
\text { porting bias) }\end{array}$ & High risk & $\begin{array}{l}\text { Only data for children who retained the beads were reported for both base- } \\
\text { line data and also outcome at } 2 \text { years. Outcomes were measured at } 6 \text { and } 12 \\
\text { months but not reported }\end{array}$ \\
\hline
\end{tabular}

Other bias

Low risk

We identified no other potential sources of bias.

dmfs: decayed, missing, and filled primary surfaces; DMFS: decayed, missing, and filled permanent surfaces; dmft: decayed, missing, and filled primary teeth; DMFT: decayed, missing, and filled permanent teeth; RCT: randomised controlled trial.

Characteristics of excluded studies [ordered by study ID]

\begin{tabular}{ll}
\hline Study & Reason for exclusion \\
\hline Aaltonen 2000 & $\begin{array}{l}\text { Not an RCT. A cohort study. Participants assigned to groups based on their risk level and "regions of } \\
\text { predetermined dental health clinic" }\end{array}$ \\
\hline Cagetti 2014 & Inappropriate intervention \\
\hline De Los Santos 1994 & $\begin{array}{l}\text { Not an RCT. It was a short duration study involving } 6 \text { participants fitted with prepared third-molar } \\
\text { extracts restrained by using acrylic holders }\end{array}$ \\
\hline Marini 1999 & $\begin{array}{l}\text { The article had stated that "the patients were randomly divided into two groups". However, infor- } \\
\text { mation from contact with study author suggested that there was no randomisation procedure - this } \\
\text { was not an RCT }\end{array}$ \\
\hline Trimpeneers 1996 & A split-mouth study. All participants received both treatments at the same time \\
\hline
\end{tabular}

$\mathrm{RCT}$ : randomised controlled trial.

\section{DATA AND ANALYSES}


Comparison 1. Slow-release fluoride device versus control

\begin{tabular}{lllll}
\hline Outcome or subgroup title & No. of studies & $\begin{array}{l}\text { No. of partici- } \\
\text { pants }\end{array}$ & Statistical method & Effect size \\
\hline $\begin{array}{l}1 \text { Change of caries (increase in decayed, missing, } \\
\begin{array}{l}\text { and filled permanent teeth (DMFT)) at 2 years } \\
\text { compared to baseline }\end{array}\end{array}$ & 63 & $\begin{array}{l}\text { Mean Difference (IV, } \\
\text { Fixed, 95\% Cl) }\end{array}$ & $\begin{array}{l}-0.72[-1.23, \\
-0.21]\end{array}$ \\
\hline $\begin{array}{l}2 \text { Change of caries (increase in decayed, missing, } \\
\begin{array}{l}\text { and filled permanent surfaces (DMFS)) at 2 years } \\
\text { compared to baseline }\end{array}\end{array}$ & 63 & Mean Difference (IV, & $-1.52[-2.68$, \\
\hline
\end{tabular}

Analysis 1.1. Comparison 1 Slow-release fluoride device versus control, Outcome 1 Change of caries (increase in decayed, missing, and filled permanent teeth (DMFT)) at 2 years compared to baseline.

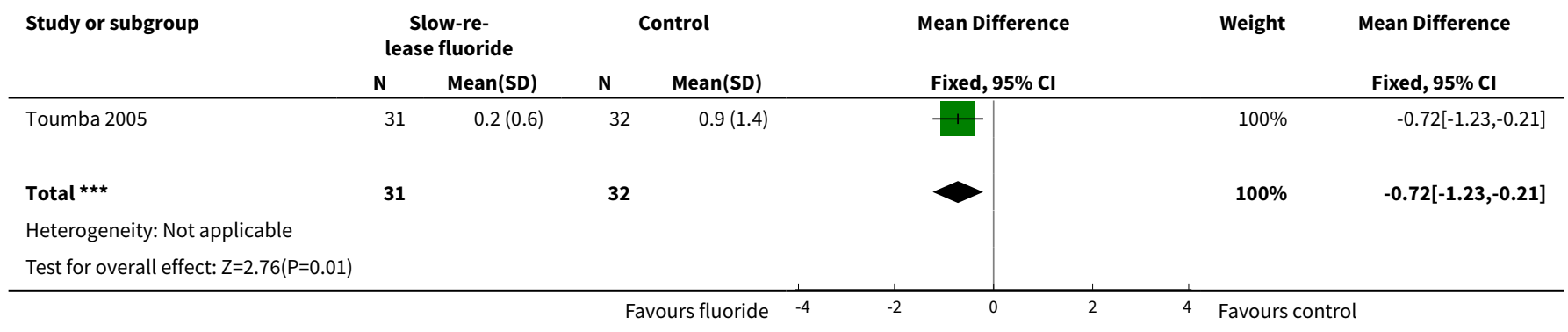

Analysis 1.2. Comparison 1 Slow-release fluoride device versus control, Outcome 2 Change of caries (increase in decayed, missing, and filled permanent surfaces (DMFS)) at 2 years compared to baseline.

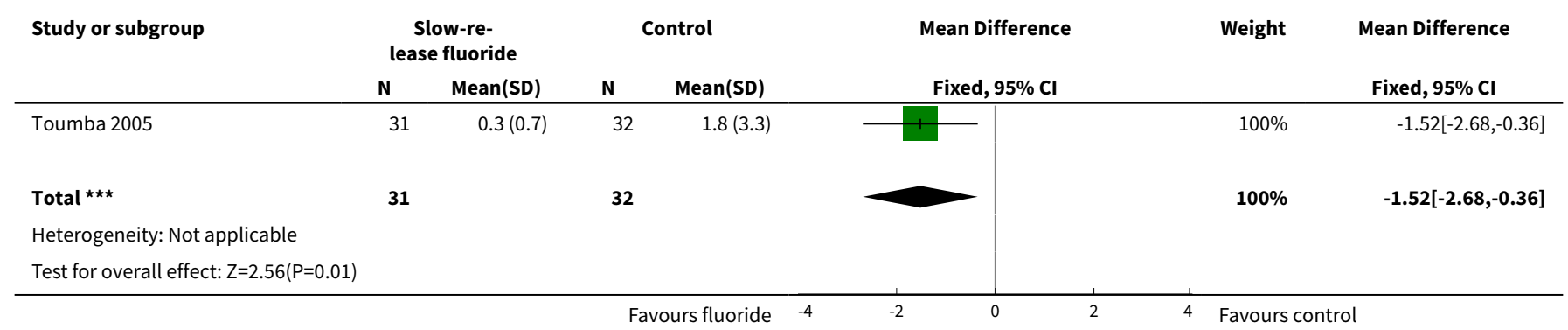

\section{A P P E N D I CES}

\section{Appendix 1. Cochrane Oral Health's Trials Register search strategy}

$\# 1$ (teeth and (cavit* or caries or carious or decay* ${ }^{*}$ or lesion* or deminerali* or reminerali*)) [REFERENCE] [STANDARD] \#2 (tooth and (cavit* or caries or carious or decay ${ }^{\star}$ or lesion* or deminerali* or reminerali*)) [REFERENCE] [STANDARD] \#3 (dental and (cavit* or caries or carious or decay* or lesion* or deminerali* or reminerali*)) [REFERENCE] [STANDARD] \#4 (enamel and (cavit* or caries or carious or decay* or lesion* or deminerali* or reminerali*)) [REFERENCE] [STANDARD] \#5 (dentin and (cavit* or caries or carious or decay ${ }^{\star}$ or lesion* ${ }^{\star}$ or deminerali* or reminerali*)) [REFERENCE] [STANDARD]

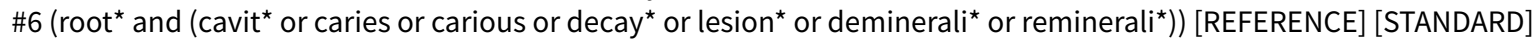
$\# 7$ \#1 or \#2 or \#3 or \#4 or \#5 or \#6 [REFERENCE] [STANDARD] 
\#8 fluorid* [REFERENCE] [STANDARD]

\#9 $\left(\right.$ slow $^{\star}$ and $\left(\right.$ releas $^{*}$ or action $\left.\left.{ }^{\star}\right)\right)$ [REFERENCE] [STANDARD]

$\# 10$ ((delay ${ }^{\star}$ or prolong ${ }^{\star}$ or control ${ }^{\star}$ or sustain $^{\star}$ or timed $\left.{ }^{\star}\right)$ and $\left(\right.$ releas $^{\star}$ or action $\left.^{\star}\right)$ ) [REFERENCE] [STANDARD]

\#11 (glass and (bead* or devic $\left.{ }^{\star}\right)$ ) [REFERENCE] [STANDARD]

\#12 ("copolymer acrylic reservoir" or "membrane controlled reservoir" or "copolymer membrane" or "hydroxyapatite Eudraglit")

[REFERENCE] [STANDARD]

\#13 \#9 or \#10 or \#11 or \#12 [REFERENCE] [STANDARD]

$\# 14 \# 7$ and \#8 and \#13 [REFERENCE] [STANDARD]

\section{Appendix 2. Cochrane Central Register of Controlled Trials (CENTRAL) search strategy}

\#1 [mh "Tooth demineralization"]

\#2 (teeth near/5 (cavit* or caries or carious or decay ${ }^{\star}$ or lesion* ${ }^{\star}$ or deminerali* or reminerali $\left.{ }^{\star}\right)$ )

\#3 (tooth near/5 (cavit* or caries or carious or decay* or lesion* or deminerali* or reminerali*))

\#4 (dental near/5 (cavit* or caries or carious or decay* or lesion* or deminerali* or reminerali*))

\#5 (enamel near $/ 5$ (cavit* or caries or carious or decay* or lesion* or deminerali* or reminerali*))

\#6 (dentin near/5 (cavit* or caries or carious or decay* or lesion* or deminerali* or reminerali*))

$\# 7$ ( root $^{\star}$ near $/ 5$ (cavit ${ }^{\star}$ or caries or carious or decay* or lesion* or deminerali* or reminerali*))

$\# 8 \# 1$ or \#2 or \#3 or \#4 or \#5 or \#6 or \#7

\#9 [mh Fluorides]

$\# 10$ fluorid $^{\star}$

$\# 11 \# 9$ or \#10

\#12 [mh^^"Delayed action preparations"]

\#13 (slow* near/5 (action* or releas*))

\#14 ((delay ${ }^{\star}$ or prolong ${ }^{\star}$ or control* or sustain ${ }^{\star}$ or timed $\left.{ }^{\star}\right)$ near $/ 5\left(\right.$ releas $^{\star}$ or action $\left.\left.{ }^{\star}\right)\right)$

\#15 ("copolymer acrylic reservoir" or "membrane controlled reservoir" or "copolymer membrane" or "hyroxyapatite Eudraglit")

\#16 \#12 or \#13 or \#14 or \#15

$\# 17 \# 8$ and \#11 and \#16

\section{Appendix 3. MEDLINE (Ovid) search strategy}

1. exp Tooth demineralization/

2. (teeth adj5 (cavit\$ or caries or carious or decay\$ or lesion $\$$ or deminerali\$ or reminerali\$)).mp.

3. (tooth adj5 (cavit\$ or caries or carious or decay\$ or lesion\$ or deminerali\$ or reminerali\$)).mp.

4. (dental adj5 (cavit\$ or caries or carious or decay\$ or lesion\$ or deminerali\$ or reminerali\$)).mp.

5. (enamel adj5 (cavit\$ or caries or carious or decay $\$$ or lesion $\$$ or deminerali\$ or reminerali\$)).mp.

6. (dentin adj5 (cavit\$ or caries or carious or decay\$ or lesion\$ or deminerali\$ or reminerali\$)).mp.

7. (root adj5 (cavit\$ or caries or carious or decay $\$$ or lesion $\$$ or deminerali\$ or reminerali\$)).mp.

8. or/1-7

9. exp Fluorides/

10. fluorid\$.mp.

11.9 or 10

12. Delayed action preparations/

13. (slow\$ adj5 (releas\$ or action\$)).mp.

14. ((delay\$ or prolong\$ or control\$ or sustain\$ or timed\$) adj5 (releas\$ or action\$)).mp.

15. (glass adj3 (bead\$ or devic\$)).mp.

16. ("copolymer acrylic reservoir" or "membrane controlled reservoir" or "copolymer membrane" or "hydroxyapatite Eudraglit").mp.

17. or/12-16

18. 8 and 11 and 17

\section{Appendix 4. Embase (Ovid) search strategy}

1. Dental caries/

2. (teeth adj5 (cavit\$ or caries or carious or decay\$ or lesion\$ or deminerali\$ or reminerali\$)).mp.

3. (tooth adj5 (cavit\$ or caries or carious or decay\$ or lesion\$ or deminerali\$ or reminerali\$)).mp.

4. (dental adj5 (cavit\$ or caries or carious or decay\$ or lesion $\$$ or deminerali\$ or reminerali\$)).mp.

5. (enamel adj5 (cavit\$ or caries or carious or decay $\$$ or lesion\$ or deminerali\$ or reminerali\$)).mp.

6. (dentin adj5 (cavit\$ or caries or carious or decay\$ or lesion\$ or deminerali\$ or reminerali\$)).mp.

7. (root adj5 (cavit\$ or caries or carious or decay\$ or lesion $\$$ or deminerali\$ or reminerali\$)).mp.

8. or/1-7

9. Fluoride/

10. fluorid\$.mp.

11.9 or 10 
12. Delayed release formulations/

13. (slow\$ adj5 (releas\$ or action\$)).mp.

14. ((delay\$ or prolong\$ or control\$ or sustain\$ or timed\$) adj5 (releas\$ or action\$)).mp.

15. (glass adj3 (bead\$ or devic\$)).mp.

16. ("copolymer acrylic reservoir" or "membrane controlled reservoir" or "copolymer membrane" or "hydroxyapatite Eudraglit").mp.

17. or/12-16

18. 8 and 11 and 17

\section{Appendix 5. US National Institutes of Health Ongoing Trials Register (ClinicalTrials.gov) and World Health Organization International Clinical Trials Registry Platform search strategy}

caries and fluoride and slow release

caries and fluoride and delayed release

caries and fluoride and controlled release

caries and fluoride and sustained release

\section{WHAT'S NEW}

\begin{tabular}{lll}
\hline Date & Event & Description \\
\hline 3 April 2018 & Review declared as stable & $\begin{array}{l}\text { This review will not be updated until a substantial body of evi- } \\
\text { dence on the topic becomes available. If trials are conducted and } \\
\text { found eligible for inclusion in the future, the review would then } \\
\text { be updated accordingly. }\end{array}$ \\
\hline
\end{tabular}

\section{HISTORY}

Protocol first published: Issue 1, 2005

Review first published: Issue 4, 2006

\begin{tabular}{lll}
\hline Date & Event & Description \\
\hline 23 January 2018 & $\begin{array}{l}\text { New citation required but conclusions } \\
\text { have not changed }\end{array}$ & $\begin{array}{l}\text { Searches updated, no new studies for inclusion, conclusions re- } \\
\text { main the same. Minor edits. }\end{array}$ \\
\hline 23 January 2018 & New search has been performed & $\begin{array}{l}\text { Searches updated 23 January 2018. We did not find any new } \\
\text { studies for inclusion. }\end{array}$ \\
\hline 18 April 2016 & Amended & Minor amendment. \\
\hline 13 August 2014 & New citation required but conclusions & $\begin{array}{l}\text { Methods updated and changes to authorship and the format of } \\
\text { the review, including edits to the outcomes list to reflect the key } \\
\text { patient outcomes required for the 'Summary of findings' table. } \\
\text { Clarified intentions of inclusion/exclusion criteria. Removed } \\
\text { 'quasi-randomised' trials, stated inclusion of non-blinded stud- } \\
\text { ies and exclusion of cross-over trials. } \\
\text { Only includes trials with treatment and follow-up of at least 1 } \\
\text { year. }\end{array}$ \\
\hline
\end{tabular}

\begin{tabular}{lll}
\hline 13 August $2014 \quad$ New search has been performed & $\begin{array}{l}\text { Searches updated 13 August 2014. We did not find any new stud- } \\
\text { ies for inclusion. }\end{array}$
\end{tabular}

1 August $2008 \quad$ Amended Converted to new review format.




\section{CONTRIBUTIONS OF AUTHORS}

Lee Yee Chon (LYC): literature searching.

LYC and Lorna Dobbyn-Ross (LDR): selection of potentially eligible studies.

LYC, LDR, and Smriti Bhakta (SB): quality assessment.

Jan Clarkson (JC): revealed results and resolved conflicts by discussion.

All authors contributed to writing the review.

\section{DECLARATIONSOF INTEREST}

Lee Yee Chon: no interests to declare.

Jan E Clarkson: no interests to declare. I am Co-ordinating Editor of Cochrane Oral Health.

Lorna Dobbyn-Ross: no interests to declare.

Smriti Bhakta: no interests to declare.

\section{SOURCES OF SUPPORT}

\section{Internal sources}

- Scottish Executive Chief Scientist Office, UK.

\section{External sources}

- National Institute for Health Research (NIHR), UK.

This project was supported by the NIHR, via Cochrane Infrastructure funding to Cochrane Oral Health. The views and opinions expressed herein are those of the review authors and do not necessarily reflect those of the Systematic Reviews Programme, the NIHR, the NHS or the Department of Health.

- Cochrane Oral Health Global Alliance, Other.

The production of Cochrane Oral Health reviews has been supported financially by our Global Alliance since 2011 (oralhealth.cochrane.org/partnerships-alliances). Contributors over the past year have been the American Association of Public Health Dentistry, USA; AS-Akademie, Germany; the British Association for the Study of Community Dentistry, UK; the British Society of Paediatric Dentistry, UK; the Canadian Dental Hygienists Association, Canada; the Centre for Dental Education and Research at All India Institute of Medical Sciences, India; the National Center for Dental Hygiene Research \& Practice, USA; New York University College of Dentistry, USA; NHS Education for Scotland, UK; and the Swiss Society for Endodontology, Switzerland.

\section{DIFFERENCES BETWEEN PROTOCOL AND REVIEW}

In the 2014 update, the methods section was edited to add clarity to the inclusion criteria and data analysis plans. The most important change was the addition of a minimum duration of study or intervention ( 1 year). We removed 'quasi-randomised' trials, stated inclusion of non-blinded studies and exclusion of cross-over trials.

\section{NOTES}

This review will not be updated until a substantial body of evidence on the topic becomes available. If trials are conducted and found eligible for inclusion in the future, the review would then be updated accordingly.

\section{N DEX TERMS}

\section{Medical Subject Headings (MeSH)}

Cariostatic Agents [*administration \& dosage]; DMF Index; Delayed-Action Preparations [administration \& dosage]; Dental Caries [* prevention \& control]; Fluorides [ ${ }^{\star}$ administration \& dosage]; Glass; Randomized Controlled Trials as Topic

\section{MeSH check words}

Child; Humans 